\title{
Severe Oro-laryngeal Thrush Following Excessive Use of Steroid Inhaler
}

\author{
Marina $\mathrm{MB}^{\mathrm{a}}$, Ramli $\mathrm{R}^{\mathrm{b}}$ and Primuharsa Putra SHAc \\ ${ }^{a}$ Department of Otorhinolaryngology-Head \& Neck Surgery, ${ }^{b}$ Department of Oral \& Maxillofacial Surgery, \\ Universiti Kebangsaan Malaysia Medical Centre, 'Ear, Nose \& Throat - Head \& Neck Consultant Clinic, KPJ \\ Seremban Specialist Hospital
}

\begin{abstract}
Introduction: Inhaled steroids such as fluticasone propionate and beclomethasone dipropionate play an important role in the treatment of bronchial asthma. Its usage facilitates disease control in asthmatic patients, resulting in improved quality of life. Because of its benefit, the inhaled steroid is used extensively, at higher doses and for longer duration. However, the localized effects of inhaled corticosteroids on oral/laryngeal mucosa, such as fungal infections can be problematic. Case Report: We report a case of oropharyngeal and laryngeal candidiasis following a long period and high doses of inhaled steroid in a 42-year-old male. He presented with a complaint of increasing tiredness, phlegm, intermittent wheezing and hoarseness for 2-3 months. There was no weight loss or loss of appetite. He has been using inhaled steroids and long acting bronchodilators in increasing doses for his claimed 'wheezing' despite the negative history of asthma. The inhaled steroids were fluticasone dipropionate at doses of 500-100 mcg daily for 2-3 months. Results: Examination revealed widespread oral thrush involving the oral cavity, oropharynx and larynx. There was no cushingoid habitus. His muscle power was of 5/5 bilaterally and his lungs were clear. Lung function and chest film were also normal. The steroid was stopped immediately and flucanozole and nystatin syrup were prescribed. The patient made an uneventful and complete recovery. Conclusion: We conclude that patients on inhaled corticosteroids should be monitored for local side effects. Physicians should be aware not only of the systemic but also of the local side effects of inhaled corticosteroids. Patients may increase doses without the knowledge of their physicians and subsequently suffer the adverse effects either local or systemic.
\end{abstract}

KEYWORDS: Oro-laryngeal, candidiasis, thrush

Corresponding author;

Dr Primuharsa Putra

KPJ Seremban Specialist Hospital, Lot 6219 \& 6220,

Jalan Toman Satu, Kemayan Square,

70200 Seremban, Negeri Sembilan

e-mail: putrani@yahoo.co.uk,

primuharsa.putra@gmail.com 